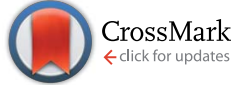

Cite this: RSC Adv., 2015, 5, 59437

Received 26th May 2015

Accepted 1st July 2015

DOI: $10.1039 / c 5 r a 09892 k$

www.rsc.org/advances

\section{Electrochemistry of actinides on reduced graphene oxide: craving for the simultaneous voltammetric determination of uranium and plutonium in nuclear fuel}

\author{
Saurav K. Guin, * Arvind S. Ambolikar and J. V. Kamat
}

\begin{abstract}
The aqueous electrochemistry of plutonium $(\mathrm{Pu})$ has been explored for the first time on the reduced graphene oxide modified glassy carbon electrode (rGO/GC). It has been confirmed that $\mathrm{rGO} / \mathrm{GC}$ can catalyse the $\mathrm{Pu}(\mathrm{IV}) / \mathrm{Pu}(\mathrm{III})$ redox reaction in $1 \mathrm{M} \mathrm{H}_{2} \mathrm{SO}_{4}$ and that finally leads to the high analytical sensitivity of anodic square wave voltammetric determination of Pu. However, the sensitivity of $\mathrm{rGO} / \mathrm{GC}$ decreases in the actual nuclear fuel sample [i.e. Mark-I $(\mathrm{U}, \mathrm{Pu}) \mathrm{C}$ fuel dissolved in $1 \mathrm{M} \mathrm{H}_{2} \mathrm{SO}_{4}$ ] due to the interference of uranium (U). Furthermore, the cathodic square wave voltammograms of $U(\mathrm{vl})$ in the sample solution have been found to be very inconsistent. That inconsistency is explained by the interfacial coupled chemical reaction between U(IV) (just produced at the working electrode) and Pu(IV) diffusing from the bulk of the solution to the vicinity of the working electrode. That is why the quantitative determination of uranium in the presence of plutonium is not feasible by simple voltammetric techniques on any working electrode. Although rGO/GC shows good analytical robustness, reproducibility, repeatability, fast analysis and least requirement of additional reagents; but challenge still exists in the analytical merits for the determination of Pu in nuclear fuel sample in competition with the biamperometric method.
\end{abstract}

\section{Introduction}

Electricity or power is one of the most critical components of infrastructure affecting the economic growth and welfare of India. India's three-stage atomic energy programme has been planned for a comprehensive mission-oriented long-term sustainable generation of electricity. In the first stage, India has reached to a total nuclear plant capacity of $5780 \mathrm{MW}$ of electricity by safely operating eighteen pressurised heavy water reactors, two boiling water reactors and one pressurised water reactor. ${ }^{1}$ The Fast Breeder Test Reactor (FBTR) built at Indira Gandhi Centre for Atomic Research, Kalpakkam, is a fore-

Fuel Chemistry Division, Bhabha Atomic Research Centre, Trombay, Mumbai-400 085, India. E-mail: sauravkrguin@yahoo.co.in; skguin@barc.gov.in; Fax: +91-22-25505151; Tel: +91-22-2559-4598 runner in the second stage of the Indian nuclear power programme. The reactor was made critical with a small core containing hyper-stoichiometric mixed plutonium $(\mathrm{Pu})$-uranium (U) carbide $\left(\mathrm{Pu}_{0.7} \mathrm{U}_{0.3}\right) \mathrm{C}$ (Mark-I) as a driver fuel. ${ }^{2}$ On this platform, precise and accurate analytical techniques are essential to control the desired quality of the nuclear fuel as well as to account the nuclear materials needed for non-proliferation and safety purposes.

The uranium and plutonium in a nuclear fuel sample can be simultaneously determined by $\alpha$-spectrometry, ${ }^{3}$ spectrophotometry, ${ }^{4-7}$ thermal ionization mass spectrometry, ${ }^{8}$ neutron activation analysis, ${ }^{9}$ potentiometry ${ }^{10}$ etc. Redox titration methods, employing a visual indicator or electrometric end point detection, are widely used for the determination of uranium and plutonium independently in the uranium-plutonium mixed oxides. ${ }^{11-19}$ The major issue in the quantitative redox titration of a mixed uranium-plutonium solution is the interfering redox reaction between $\mathrm{U}(\mathrm{Iv})$ and $\mathrm{Pu}(\mathrm{Iv})$ in acidic solutions. Following discussed redox titrimetric methodologies have been strategically developed to separately determine $\mathrm{U}$ and $\mathrm{Pu}$ avoiding their mutual interference. Plutonium is determined by the redox titration method developed by J. L. Drummond and R. A. Grant. In this method, $\mathrm{Pu}(\mathrm{III})$ and $\mathrm{Pu}(\mathrm{Iv})$ are oxidized to $\mathrm{Pu}(\mathrm{VI})$ by excess argentic oxide ( $\mathrm{AgO}$ ) in $1 \mathrm{M} \mathrm{H}_{2} \mathrm{SO}_{4}$ solution followed by the destruction of excess AgO by sulphamic acid. Then $\mathrm{Pu}(\mathrm{vI})$ is quantitatively reduced to $\mathrm{Pu}(\mathrm{Iv})$ by known excess of standard $\mathrm{Fe}(\mathrm{II})$, which is titrated with standard potassium dichromate $\left(\mathrm{K}_{2} \mathrm{Cr}_{2} \mathrm{O}_{7}\right)$ solution. If $\mathrm{U}$ is present in the solution then it exists as $\mathrm{U}(\mathrm{vI})$ and thus it does not interfere in the determination of $\mathrm{Pu}(\mathrm{Iv}) \cdot{ }^{19}$ Uranium is determined separately by the Davies and Gray method, ${ }^{18}$ modified by the New Brunswick Laboratory. ${ }^{11}$ In this method, the $\mathrm{U}(\mathrm{vI})$ solution (in $1 \mathrm{M} \mathrm{H}_{2} \mathrm{SO}_{4}+$ $12 \mathrm{M} \mathrm{H}_{3} \mathrm{PO}_{4}$ ) is quantitatively reduced to $\mathrm{U}(\mathrm{Iv})$ by excess $\mathrm{Fe}(\mathrm{II})$, which is selectively oxidized by the addition of a solution containing sulphamic acid, ammonium molybdate and nitric acid. Then the reaction mixture is diluted by $1 \mathrm{M} \mathrm{H}_{2} \mathrm{SO}_{4}$ (containing catalytic amount of $\mathrm{V}(\mathrm{Iv})$ ) down to $3 \mathrm{M} \mathrm{H}_{3} \mathrm{PO}_{4}$ concentration. Under this condition, $\mathrm{U}(\mathrm{Iv})$ is oxidized to $\mathrm{U}(\mathrm{VI})$ by reducing $\mathrm{Fe}(\mathrm{III})$ 
to $\mathrm{Fe}(\mathrm{II})$, which is titrated by standard $\mathrm{K}_{2} \mathrm{Cr}_{2} \mathrm{O}_{7}$ solution. If the solution contains $\mathrm{Pu}$, it does not interfere in the end point result, because whatever $\mathrm{Pu}(\mathrm{Iv}, \mathrm{vI})$ is reduced to $\mathrm{Pu}(\mathrm{III})$ by $\mathrm{Fe}$ (II) in the reduction step; the same amount of $\mathrm{Pu}(\mathrm{III})$ is back oxidized by $\mathrm{Mo}(\mathrm{vI})$ in the oxidation step to $\mathrm{Pu}(\mathrm{Iv})$. However, the recovery of $\mathrm{Pu}$ from the highly complexing $\mathrm{H}_{3} \mathrm{PO}_{4}$ medium is cumbersome. Therefore, a couple of alternative redox titrimetric methods have been developed in our laboratory for biamperometric determination of $\mathrm{U}$ and $\mathrm{Pu} .^{\mathbf{1 2 , 1 4 , 1 6}}$ However, those redox titrimetric methods mostly require separate exercise and reagents for the determination of $\mathrm{U}$ and $\mathrm{Pu}$ in the same sample.

Controlled potential coulometry is another well established and routinely employed technique for precise and accurate determination of uranium and plutonium. ${ }^{20-26}$ The quantitative conversion of $\mathrm{U}(\mathrm{vI})$ to $\mathrm{U}(\mathrm{IV})$ in $1 \mathrm{M} \mathrm{H}_{2} \mathrm{SO}_{4}$ is carried out at -0.325 $\mathrm{V}$ versus saturated calomel electrode (SCE) on mercury pool electrode for the determination of uranium. Similarly, the $\mathrm{Pu}(\mathrm{III})$ is quantitatively oxidized to $\mathrm{Pu}(\mathrm{IV})$ in $\mathrm{H}_{2} \mathrm{SO}_{4}$ at $0.7 \mathrm{~V}$ versus SCE on platinum wire gauge electrode for the determination of plutonium. Therefore, two different working electrodes are necessary for the coulometric determination of $\mathrm{U}$ and $\mathrm{Pu}$. $\mathrm{A}$ couple of initiatives have been taken to replace two separate working electrodes by single working electrode (like graphite electrode etc.) to simultaneously determine $\mathrm{U}$ and $\mathrm{Pu}$ in the same sample. ${ }^{27-29}$ However, the chance of interference from the redox reaction between $\mathrm{Pu}(\mathrm{Iv})$ and $\mathrm{U}(\mathrm{Iv})$ still exists during the coulometric determination of $\mathrm{U}$ in the presence of $\mathrm{Pu}$ on a single working electrode. Therefore, a pre-reduction step at $0.085 \mathrm{~V} v s$. SCE is performed to completely reduce all $\mathrm{Pu}$ into $\mathrm{Pu}(\mathrm{III})$ and then the potential is set at $-0.325 \mathrm{~V} v s$. SCE for the reduction of $\mathrm{U}(\mathrm{vI})$ to $\mathrm{U}(\mathrm{IV})$. Although coulometry is an absolute electroanalytical method, but the total duration of analysis for a sample is effectively long.

In contrast, voltammetry is one of the rapid electroanalytical techniques capable for fast, precise and accurate quantification of the analytes. ${ }^{30}$ Therefore; it was of interest to develop easier and rapid voltammetric methodology for the determination of uranium and plutonium in the nuclear fuels. The graphene materials have been emerging in the electrocatalysis and electroanalysis as the potent surface modifying agents for the working electrodes, where the graphene materials can selectively increase the rate of heterogeneous electron transfer as well as the selectivity of the determination of the analyte. Authors have recently explored the electrocatalytic action of electrochemically reduced graphene oxide (rGO) modified glassy carbon electrode (i.e. $\mathrm{rGO} / \mathrm{GC}$ ) in the electrochemistry of $\left[\mathrm{U}^{\mathrm{VI}} \mathrm{O}_{2}\left(\mathrm{CO}_{3}\right)_{3}\right]^{4-} /\left[\mathrm{U}^{\mathrm{V}} \mathrm{O}_{2}\left(\mathrm{CO}_{3}\right)_{3}\right]^{5-}$ redox couple. ${ }^{31}$ There it was evidenced that in situ generated topological defects introduce significant in-plane distortions and strains in the surrounding lattice of rGO resulting into its higher reactivity towards the electrochemistry of U. However, the aqueous electrochemistry of plutonium on graphene material is yet unexplored. Therefore, the prime focus of this article is to study the electrochemistry of $\mathrm{Pu}(\mathrm{IV}) / \mathrm{P}$ (III) redox couple in $1 \mathrm{M} \mathrm{H}_{2} \mathrm{SO}_{4}$ on $\mathrm{rGO} / \mathrm{GC}$. In addition to this it was found in the literature that singlewalled carbon nanotube modified gold electrode, without addressing any interference from the interfacial redox chemistry of U(Iv) and Pu(Iv), apparently showed the ability to precisely, accurately and simultaneously determine $\mathrm{U}$ and $\mathrm{Pu}$ down to $\mu \mathrm{M}$ (or ng $\mathrm{g}^{-1}$ to $\mu \mathrm{g} \mathrm{g}^{-1}$ ) concentration ranges! ${ }^{32}$ Thus we have also explored the validity of the simple voltammetric techniques on the solid electrodes for the simultaneous quantitative determination of uranium and plutonium in FBTR fuel. This paper evidently reports that the interference from the interfacial redox chemistry of $\mathrm{U}(\mathrm{Iv})$ and $\mathrm{Pu}(\mathrm{IV})$ restricts the quantitative determination of uranium in the presence of plutonium on any solid electrodes (irrespective of the type of surface modifications) by simple voltammetric methods such as cyclic voltammetry, differential pulse voltammetry and square wave voltammetry.

\section{Experimental}

Caution! ${ }^{239} \mathrm{Pu}$ is an $\alpha$-active nuclide with a half-life of $2.4 \times 10^{4}$ years. This corresponds to the production of $138 \times 10^{6}$ $\alpha$-particles $\min ^{-1} \mathrm{mg}^{-1}$ of $\mathrm{Pu}$. This radioactive material must be handled carefully in a radiological facility with appropriate equipment to avoid any health risk caused by the radiation exposure. Therefore, all the experiments were performed with proper training and great care in a suitable place under safe conditions. $^{33}$

Guaranteed reagent (G.R.) grade sulphuric acid $\left(\mathrm{H}_{2} \mathrm{SO}_{4}\right)$, extra pure ACS grade uranyl nitrate hexahydrate $\left[\mathrm{UO}_{2}\left(\mathrm{NO}_{3}\right)_{2} \cdot 6 \mathrm{H}_{2} \mathrm{O}\right]$ were used as received. All the solutions were prepared using ultra pure water (Milli-Q, Millipore, $18.2 \mathrm{M} \Omega \mathrm{cm}$ ). The GO purchased from $\mathrm{M} / \mathrm{s}$. Global Nanotech were used as received. The product certificate (received from M/s. Global Nanotech) is available elsewhere. ${ }^{31}$ The GC electrode was modified with GO by drop casting about $0.16 \mu \mathrm{g}$ (optimized to have least amount of capacitive current) GO dispersed in nanopure water followed by gentle drying under IR lamp. The GO modified GC electrode was electrochemically reduced by scanning the potential window from $0 \mathrm{~V}$ to $-1.6 \mathrm{~V}$ ( $v s$. $\mathrm{Ag} / \mathrm{AgCl}$ (saturated $\mathrm{KCl}$ ) reference electrode) at a scan rate of $50 \mathrm{mV} \mathrm{s}^{-1}$ for only one complete cycle in saturated $\mathrm{Na}_{2} \mathrm{CO}_{3}$ solution $(\mathrm{pH} \sim 12.3)$ as discussed elsewhere. ${ }^{31}$

A stock solution of $7.618 \mathrm{mg} \mathrm{g}^{-1}$ (or $31.87 \mathrm{mM}$ ) of standard plutonium was prepared from the solid working reference, potassium plutonium sulphate dihydrate $\left(\mathrm{K}_{4} \mathrm{Pu}\left(\mathrm{SO}_{4}\right)_{4} \cdot 2 \mathrm{H}_{2} \mathrm{O}\right)$; which was prepared in our laboratory by a method as described elsewhere. ${ }^{34}$ In brief, a mixture of $\mathrm{K}_{2} \mathrm{SO}_{4}$ and $\mathrm{Pu}\left(\mathrm{SO}_{4}\right)_{2}$ in a molar ratio of 2:1 was slowly evaporated in $1 \mathrm{M} \mathrm{H}_{2} \mathrm{SO}_{4}$ to prepare crystals of $\left(\mathrm{K}_{4} \mathrm{Pu}\left(\mathrm{SO}_{4}\right)_{4} \cdot 2 \mathrm{H}_{2} \mathrm{O}\right)$. The crystals were washed several times with absolute alcohol followed by drying in a current of air. Then the anhydrous $\mathrm{K}_{4} \mathrm{Pu}\left(\mathrm{SO}_{4}\right)_{4}$ was prepared by heating the hydrated crystals at $340{ }^{\circ} \mathrm{C}$ for about three hours until constant weight. A known amount of the anhydrous standard $\mathrm{K}_{4} \mathrm{Pu}\left(\mathrm{SO}_{4}\right)_{4}$ was quantitatively dissolved in $15 \mathrm{~mL}$ of $3 \mathrm{M} \mathrm{HNO}_{3}$ and the solution was fumed with $1 \mathrm{M} \mathrm{H}_{2} \mathrm{SO}_{4}$ to convert into sulfate form. The residue was again treated with $1 \mathrm{M} \mathrm{H}_{2} \mathrm{SO}_{4}$ and evaporated to dryness. This particular step was repeated several times to ensure the complete removal of nitrate. Finally, the stock solution of $7.618 \mathrm{mg} \mathrm{g}^{-1}$ (or $31.87 \mathrm{mM}$ ) plutonium in $1 \mathrm{M}$ 
$\mathrm{H}_{2} \mathrm{SO}_{4}$ was prepared by quantitatively diluting the residue with $1 \mathrm{M} \mathrm{H}_{2} \mathrm{SO}_{4}$.

FBTR Mark-I fuel sample solution was prepared by following the method published elsewhere. ${ }^{35}$ The fuel samples were analysed by biamperometric method with the sample solution having plutonium concentration in the range of 2-6 $\mathrm{mg} \mathrm{g}^{-1}$. The reported values (by biamperometry) of $\mathrm{U}$ and $\mathrm{Pu}$ in this sample are $1.575 \mathrm{mg} \mathrm{g}^{-1}$ and $3.799 \mathrm{mg} \mathrm{g}^{-1}$, respectively. For any conversion in the concentration units, we have used $1 \mathrm{mM}$ of $\mathrm{Pu}(\mathrm{Iv})$ and $\mathrm{U}(\mathrm{vI})$ equivalent to $0.239 \mathrm{mg} \mathrm{g}^{-1}$ of $\mathrm{Pu}(\mathrm{IV})$ and 0.238 $\mathrm{mg} \mathrm{g}^{-1}$ of $\mathrm{U}(\mathrm{vI})$, respectively.

The electrochemical experiments were performed at room temperature $(T=298 \mathrm{~K})$ in a conventional three-electrode cell by using CHI-450B electrochemical workstation. There was no uncompensated resistance in the voltammetric results. A commercial glassy carbon (GC) $(\varphi=3 \mathrm{~mm})$ or modified GC electrode was used as the working electrode, $\mathrm{Ag} / \mathrm{AgCl} / \mathrm{KCl}$ (saturated) $\left(E_{\mathrm{Ag} / \mathrm{AgCl}}=+0.197 \mathrm{~V}\right.$ vs. standard hydrogen electrode) was used as the reference electrode and a platinum wire acted as the counter electrode. All the potentials quoted are with respect to the $\mathrm{Ag} / \mathrm{AgCl}($ saturated $\mathrm{KCl}$ ) reference electrode. Prior to perform the electrochemical experiments, the working solution was purged with high purity nitrogen for 15 min to remove the dissolved oxygen from the solution. The GC electrode was polished by using alumina slurries with different powders of size down to $0.05 \mu \mathrm{m}$. After each polishing, the electrode was thoroughly rinsed with water.

\section{Results and discussion}

Fig. 1 shows the cyclic voltammogram of $10 \mathrm{mM} \mathrm{Pu(Iv)}$ in $1 \mathrm{M}$ $\mathrm{H}_{2} \mathrm{SO}_{4}$ solution on (i) GC and (ii) rGO/GC electrodes at a scan rate of $10 \mathrm{mV} \mathrm{s}^{-1}$. The cathodic $\left(E_{\mathrm{p}}^{\mathrm{c}}\right)$ and anodic $\left(E_{\mathrm{p}}^{\mathrm{a}}\right)$ peak potentials for $\mathrm{Pu}(\mathrm{Iv}) / \mathrm{Pu}(\mathrm{III})$ redox couple are appeared at $0.092 \mathrm{~V}$ and $0.666 \mathrm{~V}$, respectively, on GC (Fig. 1(i)). The separation between the peak potentials $\left(\Delta E_{\mathrm{p}}\right)$ is calculated as $0.574 \mathrm{~V}$. The cathodic peak is very broad; whereas the anodic peak is comparatively sharper. However, for the same reaction on $\mathrm{rGO} /$ $\mathrm{GC}, E_{\mathrm{p}}^{\mathrm{c}}$ is shifted to lesser cathodic potential $(0.398 \mathrm{~V})$ and $E_{\mathrm{p}}^{\mathrm{a}}$ is shifted to lesser anodic potential $(0.605 \mathrm{~V})$ leading to a narrower

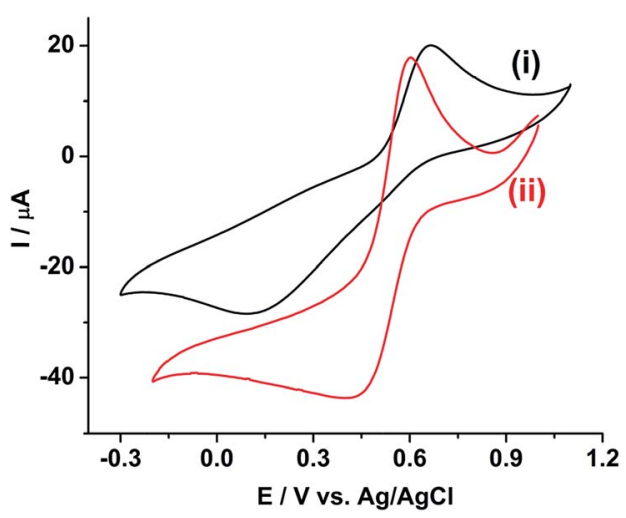

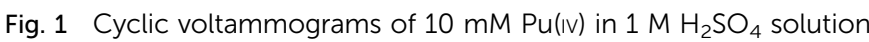
on (i) GC and (ii) rGO/GC electrodes at a scan rate of $10 \mathrm{mV} \mathrm{s}^{-1}$. peak separation $(0.207 \mathrm{~V})$ (Fig. 1(ii)). Therefore, the overpotentials for both the cathodic and anodic reactions are significantly decreased indicating that $\mathrm{rGO}$ can catalyse the electrochemistry of $\mathrm{Pu}(\mathrm{IV}) / \mathrm{Pu}(\mathrm{III})$ redox couple in $1 \mathrm{M} \mathrm{H}_{2} \mathrm{SO}_{4}$.

Fig. 2a shows the effect of the scan rates $(v)$ on the cyclic voltammograms of $10 \mathrm{mM} \mathrm{Pu(IV)}$ in $1 \mathrm{M} \mathrm{H}_{2} \mathrm{SO}_{4}$ solution on GC electrode. The flux of the analyte towards and outward the electrode increases with increasing the scan rate. Therefore, the current of the voltammograms systematically increases with increasing the scan rate. It is known that the peak current is proportional to the square root of scan rate for diffusion controlled electron transfer reaction, whereas, the peak current proportionally varies with the scan rate for adsorption controlled electron transfer reaction. Therefore, the theoretical slopes of $\ln \left(-I_{\mathrm{p}}\right)$ vs. $\ln (v)$ plot should be 0.5 and 1 for diffusion controlled and adsorption controlled electron transfer reactions, respectively. The inset of Fig. 2 a shows the linear variation of $\ln \left(-I_{\mathrm{p}}\right)$ as a function of $\ln (v)$ with a slope of $0.37\left(R^{2}=\right.$ $0.997)$ and $0.38\left(R^{2}=0.993\right)$ for (1) cathodic and (2) anodic peak currents, respectively. Therefore, it can be inferred that the redox reaction of $\mathrm{Pu}(\mathrm{Iv}) / \mathrm{Pu}(\mathrm{III})$ couple on GC is governed only by the diffusion controlled mechanism. The other electrochemical data such as $E_{\mathrm{p}}^{\mathrm{c}}, E_{\mathrm{p}}^{\mathrm{a}}, \Delta E_{\mathrm{p}}$, formal potential of the redox couple $\left(E_{0}^{\prime}\right)$; half-cathodic peak potential $\left(E_{\mathrm{p} / 2}^{\mathrm{c}}\right)$; half-anodic peak potential $\left(E_{\mathrm{p} / 2}^{\mathrm{a}}\right)$; effective charge transfer coefficient for the cathodic reaction $\left(n^{*} \alpha_{\mathrm{c}}\right)$ and effective charge transfer coefficient for the anodic reaction $\left(n^{*} \alpha_{\mathrm{a}}\right)$ are listed in Table 1 . Here, $n^{*}$ and $\alpha_{\mathrm{c}}, \alpha_{\mathrm{a}}$ designate the electron stoichiometry in the rate determining step and charge transfer coefficient for cathodic and anodic reactions, respectively. For this well characterized reaction, $n^{*}$ can be considered as equal to the stoichiometric number of electrons i.e., $n=n^{*}=1$. The $E_{0}^{\prime}, n^{*} \alpha_{\mathrm{c}}$ and $n^{*} \alpha_{\mathrm{c}}$ are calculated at each scan rate by eqn $(1-3):{ }^{36}$

$$
\begin{aligned}
E^{\prime}{ }_{0} & =\frac{\left(E_{\mathrm{p}}^{\mathrm{c}}-E_{\mathrm{p}}^{\mathrm{a}}\right)}{2} \\
n^{*} \alpha_{\mathrm{c}} & =\frac{0.04768}{\left|E_{\frac{\mathrm{p}}{2}}^{\mathrm{c}}-E_{\mathrm{p}}^{\mathrm{c}}\right|} \\
n^{*} \alpha_{\mathrm{a}} & =\frac{0.04768}{\left|E_{\mathrm{p}}^{\mathrm{a}}-E_{\mathrm{p}}^{\mathrm{a}}\right|}
\end{aligned}
$$

It can be seen from Table 1 that, the values of $E^{\prime}{ }_{0}(0.375 \pm$ $0.004 \mathrm{~V}$ vs. $\mathrm{Ag} / \mathrm{AgCl}) ; n^{*} \alpha_{\mathrm{c}}(0.23 \pm 0.02)$ and $n^{*} \alpha_{\mathrm{a}}(0.45 \pm 0.10)$ are almost independent of the scan rate; although $\Delta E_{\mathrm{p}}$ is increased from $0.574 \mathrm{~V}$ at $v=0.010 \mathrm{~V} \mathrm{~s}^{-1}$ to $0.852 \mathrm{~V}$ at $v=0.250$ $\mathrm{V} \mathrm{s}^{-1}$. This suggests that the electrochemistry of $\mathrm{Pu}(\mathrm{IV}) / \mathrm{Pu}(\mathrm{III})$ redox couple on GC electrode is quasi-reversible in nature. Since, $\mathrm{Pu}(\mathrm{Iv})$ is more stable in $1 \mathrm{M} \mathrm{H}_{2} \mathrm{SO}_{4}$ compared to $\mathrm{Pu}(\mathrm{III})$. Therefore, the small value of $\alpha_{\mathrm{c}}\left(\alpha_{\mathrm{c}}=0.23\right.$; considering $\left.n^{*}=1\right)$ is responsible for the broad cathodic peak of the $\mathrm{CV}$. It should be noted that in an old solution, a certain fraction of plutonium 

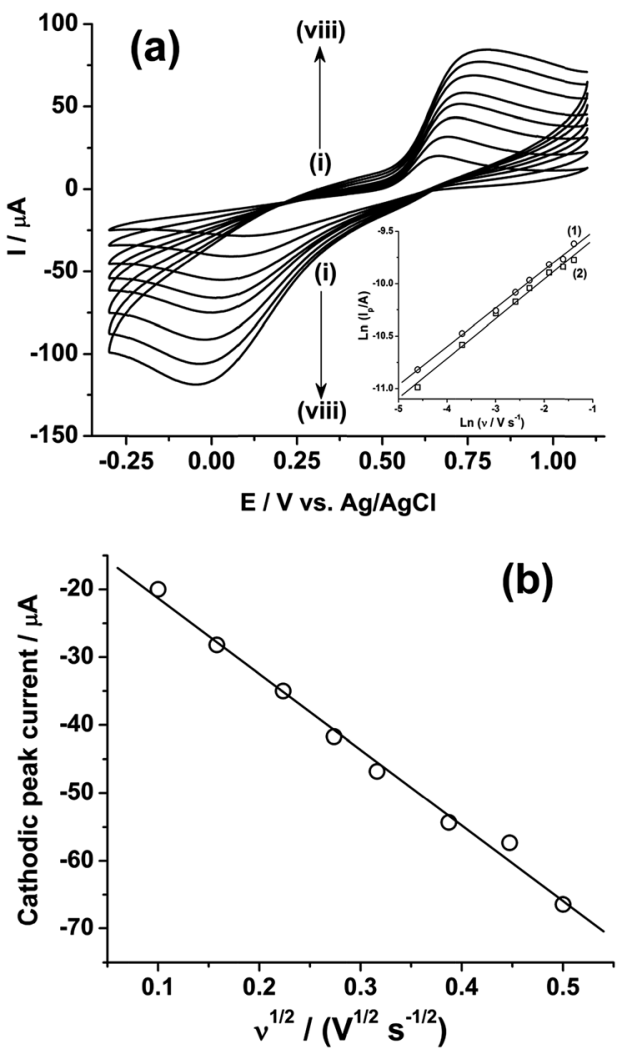

Fig. 2 (a) Cyclic voltammograms of $10 \mathrm{mM} \mathrm{Pu(Iv)} \mathrm{in} 1 \mathrm{M} \mathrm{H}_{2} \mathrm{SO}_{4}$ solution on GC electrode at a scan rate (v) of (i) 10 , (ii) 25 , (iii) 50 , (iv) 75 , (v) 100, (vi) 150, (vii) 200 and (viii) $250 \mathrm{mV} \mathrm{s}^{-1}$. The inset shows the plots of $\ln \left(I_{\mathrm{p}}\right)$ versus $\ln (v)$ for (1) cathodic and (2) anodic peaks. (b) Plot of the cathodic peak current versus the square root of the scan rate $\left(v^{1 / 2}\right)$.

Table 1 Electrochemical parameters of the cyclic voltammograms of $10 \mathrm{mM}$ Pu(Iv) in $1 \mathrm{M} \mathrm{H}_{2} \mathrm{SO}_{4}$ solution on $\mathrm{GC}$ electrode at different scan rates $(v)$

\begin{tabular}{lllllllll}
\hline$v / \mathrm{V} \mathrm{s}^{-1}$ & $E_{\mathrm{p}}^{\mathrm{c}} / \mathrm{V}$ & $E_{\mathrm{p} / 2}^{\mathrm{c}} / \mathrm{V}$ & $E_{\mathrm{p}}^{\mathrm{a}} / \mathrm{V}$ & $E_{\mathrm{p} / 2}^{\mathrm{a}} / \mathrm{V}$ & $\Delta E_{\mathrm{p}} / \mathrm{V}$ & $E_{0}^{\prime} / \mathrm{V}$ & $n^{*} \alpha_{\mathrm{c}}$ & $n^{*} \alpha_{\mathrm{a}}$ \\
\hline 0.010 & 0.092 & 0.337 & 0.666 & 0.587 & 0.574 & 0.379 & 0.19 & 0.60 \\
0.025 & 0.058 & 0.281 & 0.691 & 0.607 & 0.633 & 0.374 & 0.21 & 0.57 \\
0.050 & 0.033 & 0.239 & 0.714 & 0.618 & 0.681 & 0.373 & 0.23 & 0.50 \\
0.075 & 0.012 & 0.218 & 0.729 & 0.625 & 0.717 & 0.370 & 0.23 & 0.46 \\
0.100 & 0.001 & 0.201 & 0.743 & 0.631 & 0.742 & 0.372 & 0.24 & 0.43 \\
0.150 & -0.022 & 0.174 & 0.769 & 0.640 & 0.791 & 0.373 & 0.24 & 0.37 \\
0.200 & -0.035 & 0.149 & 0.788 & 0.649 & 0.823 & 0.377 & 0.26 & 0.34 \\
0.250 & -0.045 & 0.142 & 0.807 & 0.656 & 0.852 & 0.381 & 0.25 & 0.32
\end{tabular}

also exists in $\mathrm{Pu}(\mathrm{VI})$ state and its reduction to $\mathrm{Pu}(\mathrm{III})$ via $\mathrm{Pu}(\mathrm{IV})$ also broadens the cathodic peak.

Fig. $2 \mathrm{~b}$ shows the linear variation of $I_{\mathrm{p}}^{\mathrm{c}}$ with the square root of the scan rate $\left(v^{1 / 2}\right)$. Therefore, the diffusion coefficient $\left(D\right.$ in $\mathrm{cm}^{2}$ $\mathrm{s}^{-1}$ ) of $\mathrm{Pu}(\mathrm{Iv})$ in $1 \mathrm{M} \mathrm{H}_{2} \mathrm{SO}_{4}$ solution could be calculated as $1.2 \times$ $10^{-6} \mathrm{~cm}^{2} \mathrm{~s}^{-1}$ by eqn (4):36-41

$$
\left|I_{\mathrm{p}}^{\mathrm{c}}\right|=2.985 \times 10^{5} n A C^{*}\left(n^{*} \alpha_{\mathrm{c}}\right)^{\frac{1}{2}} D^{\frac{1}{2}} \nu^{\frac{1}{2}}
$$

where, $n, A$ and $C^{*}$ are the stoichiometric number of electron (1 in present case), area of the electrode $\left(0.071 \mathrm{~cm}^{2}\right)$ and bulk concentration of $\mathrm{Pu}(\mathrm{Iv})$. If we assume, the diffusion coefficients of $\mathrm{Pu}(\mathrm{Iv})$ and $\mathrm{Pu}(\mathrm{III})$ are equal; then we can define the kinetic parameter $(\Psi)$ as eqn $(5)::^{37-42}$

$$
\Psi=\frac{k_{0}}{\left[\frac{n \pi F D v}{R T}\right]^{\frac{1}{2}}}
$$

where,

$$
\Psi=\frac{1}{35.87169 \Delta E_{\mathrm{p}}-2.0999}
$$

and $k_{0}$ is the standard rate constant of the reduction of $\mathrm{Pu}(\mathrm{Iv})$. Therefore, $k_{0}$ of the reduction of $\mathrm{Pu}(\mathrm{Iv})$ on GC is calculated as 4.7 $\times 10^{-5} \mathrm{~cm} \mathrm{~s}^{-1}$ from the slope of the plot of $[n \pi F D v /(R T)]^{-1 / 2}$ versus $\Psi$. The reversibility factor $(\Lambda)$ of the redox reaction is defined as eqn (7): ${ }^{36,43}$

$$
\Lambda=\frac{k_{0}}{\left[\frac{n F D \nu}{R T}\right]^{\frac{1}{2}}}
$$

The values of $\Lambda$ for the redox reaction of $\mathrm{Pu}(\mathrm{Iv}) / \mathrm{Pu}$ (III) couple on GC electrode lies between $6.94 \times 10^{-2}$ (for $v=0.010 \mathrm{~V} \mathrm{~s}^{-1}$ ) and $1.39 \times 10^{-2}$ (for $v=0.250 \mathrm{~V} \mathrm{~s}^{-1}$ ) representing the quasireversible electrochemistry of $\mathrm{Pu}(\mathrm{Iv}) / \mathrm{Pu}(\mathrm{III})$ on GC electrode.

Fig. 3 shows the effect of the scan rates on the cyclic voltammograms of $10 \mathrm{mM} \mathrm{Pu}(\mathrm{Iv})$ in $1 \mathrm{M} \mathrm{H}_{2} \mathrm{SO}_{4}$ solution on $\mathrm{rGO} / \mathrm{GC}$ electrode. The current of the voltammograms is systematically increased with increasing the scan rate. The inset of Fig. 3a shows the linear variation of $\ln \left(-I_{\mathrm{p}}\right)$ as a function of $\ln (v)$ with a slope of 0.34 and 0.33 for (1) cathodic and (2) anodic peak currents, respectively. Therefore, the redox reaction of $\mathrm{Pu}(\mathrm{Iv}) /$ $\mathrm{Pu}$ (III) couple on $\mathrm{rGO} / \mathrm{GC}$ is also governed by the diffusion controlled mass transfer mechanism. Table 2 shows the values of $E_{\mathrm{p}}^{\mathrm{c}}, E_{\mathrm{p}}^{\mathrm{a}}, \Delta E_{\mathrm{p}}, E_{0}^{\prime}, E_{\mathrm{p} / 2}^{\mathrm{c}}, E_{\mathrm{p} / 2}^{\mathrm{a}}, n^{*} \alpha_{\mathrm{c}}, n^{*} \alpha_{\mathrm{a}}$ as a function of $v$ for the voltammograms of $10 \mathrm{mM} \mathrm{Pu}(\mathrm{Iv})$ in $1 \mathrm{M} \mathrm{H}_{2} \mathrm{SO}_{4}$ solution on $\mathrm{rGO} /$ GC electrode. The values of $E_{0}^{\prime}(0.465 \pm 0.022 \mathrm{~V} v s$. $\mathrm{Ag} / \mathrm{AgCl})$, $n^{*} \alpha_{\mathrm{c}}(0.24 \pm 0.05)$ and $n^{*} \alpha_{\mathrm{a}}(0.59 \pm 0.04)$ are almost independent of the scan rate; although $\Delta E_{\mathrm{p}}$ is increased from $0.207 \mathrm{~V}$ at $v=0.010 \mathrm{~V} \mathrm{~s}^{-1}$ to $0.457 \mathrm{~V}$ at $v=0.250 \mathrm{~V} \mathrm{~s}^{-1}$. This suggests that the electrochemistry of $\mathrm{Pu}(\mathrm{Iv}) / \mathrm{Pu}(\mathrm{III})$ redox couple on $\mathrm{rGO} / \mathrm{GC}$ electrode is also quasi-reversible in nature. No significant difference in the values of $E_{0}^{\prime}, n^{*} \alpha_{\mathrm{c}}$ and $n^{*} \alpha_{\mathrm{c}}$ is observed for the electrochemistry of $\mathrm{Pu}(\mathrm{Iv}) / \mathrm{Pu}$ (III) couple on $\mathrm{rGO} / \mathrm{GC}$ compared to bare GC. However, the $\Delta E_{\mathrm{p}}$ becomes significantly narrower on $\mathrm{rGO} / \mathrm{GC}$ compared to GC for all the scan rates. We have assumed that the $D$ value of $\mathrm{Pu}(\mathrm{Iv})$ should be independent of the nature of the electrode as long as the working solution is identical. Therefore, $k_{0}$ of the reduction of $\mathrm{Pu}(\mathrm{Iv})$ on $\mathrm{rGO} / \mathrm{GC}$ is calculated as $1.9 \times 10^{-4} \mathrm{~cm} \mathrm{~s}^{-1}$ from the slope of the plot of $[n \pi F D v /(R T)]^{-1 / 2}$ versus $\Psi$ considering the $D$ of $\mathrm{Pu}(\mathrm{Iv})$ as $1.2 \times$ $10^{-6} \mathrm{~cm}^{2} \mathrm{~s}^{-1}$. Therefore, the standard electron transfer rate constant for the reduction of $\mathrm{Pu}(\mathrm{Iv})$ is increased at $\mathrm{rGO} / \mathrm{GC}$ compared to bare GC. This observation is in accordance with the results of the electrochemical reduction of $\left[\mathrm{U}^{\mathrm{VI}} \mathrm{O}_{2}\left(\mathrm{CO}_{3}\right)_{3}\right]^{4-}$ 
on rGO/GC electrode. ${ }^{31}$ The value of $\Lambda$ for the redox reaction of $\mathrm{Pu}(\mathrm{IV}) / \mathrm{Pu}(\mathrm{III})$ couple on $\mathrm{rGO} / \mathrm{GC}$ electrode lies between $2.8 \times$ $10^{-1}$ (for $v=0.010 \mathrm{~V} \mathrm{~s}^{-1}$ ) and $5.6 \times 10^{-2}$ (for $v=0.250 \mathrm{~V} \mathrm{~s}^{-1}$ ) representing the quasi-reversible electrochemistry of $\mathrm{Pu}(\mathrm{Iv}) /$ $\mathrm{Pu}(\mathrm{III})$ on $\mathrm{rGO} / \mathrm{GC}$ electrode. The extent of the reversibility for the same redox couple increased on $\mathrm{rGO} / \mathrm{GC}$ compared to bare GC. Therefore, the increase in the $k_{0}$ value of the electron transfer reaction as well as the enhancement of the electrochemical reversibility at $\mathrm{rGO} / \mathrm{GC}$ could be considered as the signature of electrocatalysis, which is mostly imposed by the in situ generated topological defects of $\mathrm{rGO} / \mathrm{GC} .^{\mathbf{3 1 , 4 4 , 4 5}}$

Fig. 4a shows the square wave voltammogram (SWV) of 10 $\mathrm{mM} \mathrm{Pu}$ in $1 \mathrm{M} \mathrm{H}_{2} \mathrm{SO}_{4}$ in the cathodic scan direction. The GC electrode shows a broad cathodic SWV peak with the peak potential at $0.150 \mathrm{~V}$ and peak current of $-5.77 \mu \mathrm{A}$ (Fig. $4 \mathrm{a}(\mathrm{i})$ ). The peak potential decreases to $0.564 \mathrm{~V}$ with increasing the peak current to $-27.5 \mu \mathrm{A}$ at $\mathrm{rGO} / \mathrm{GC}$ electrode (Fig. $4 \mathrm{a}(\mathrm{ii})$ ). As discussed in the earlier sections, due to the small value of the effective charge transfer coefficient for the cathodic reaction, the broad reduction peak is observed on both the GC and $\mathrm{rGO} /$ GC electrodes. Therefore, the selection of cathodic SWV is not expected to be suitable for the quantitative analysis of plutonium. On the other hand, the GC electrode shows a comparatively sharper SWV anodic peak with the peak potential at 0.611 $\mathrm{V}$ and peak current of $10.4 \mu \mathrm{A}$ (Fig. $4 \mathrm{~b}(\mathrm{i})$ ). The peak potential is decreased to $0.547 \mathrm{~V}$ with increasing the peak current to $51.0 \mu \mathrm{A}$ for the same reaction at $\mathrm{rGO} / \mathrm{GC}$ electrode (Fig. $4 \mathrm{~b}$ (ii)). The sharper oxidation peaks are attributed to the higher value of the effective charge transfer coefficient for the anodic reaction. Therefore, the quantitative analysis of plutonium samples could be done by anodic SWV and thus, henceforth we have restricted our studies to the anodic SWV (ASWV) of plutonium.

Fig. 5 shows the ASWV of (i) 2.17, (ii) 2.86, (iii) 3.38 and (iv) $3.81 \mathrm{mg} \mathrm{g}^{-1}$ of $\mathrm{Pu}$ in $1 \mathrm{M} \mathrm{H}_{2} \mathrm{SO}_{4}$ on $\mathrm{rGO} / \mathrm{GC}$. The peak current $\left(I_{\mathrm{p}}\right)$ is linearly increased with increasing the concentration of $\mathrm{Pu}$ (inset of Fig. 5) with a sensitivity of $25.8 \mu \mathrm{A}\left(\mathrm{mg} \mathrm{g}^{-1}\right)^{-1}$. Fig. 6a shows ten repetitive ASWVs of the fuel sample on $\mathrm{rGO} / \mathrm{GC}$ in the scan potential range $0.35 \mathrm{~V}$ to $0.75 \mathrm{~V}$ with $I_{\mathrm{p}}=73.7 \pm 0.06 \mu \mathrm{A}$.

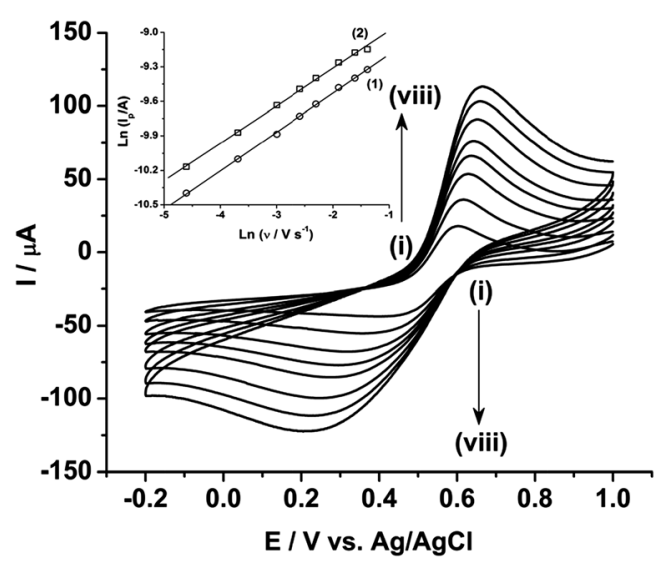

Fig. 3 Cyclic voltammograms of $10 \mathrm{mM} \mathrm{Pu(IV)}$ in $1 \mathrm{M} \mathrm{H}_{2} \mathrm{SO}_{4}$ solution on rGO/GC electrode at a scan rate (v) of (i) 10 , (ii) 25 , (iii) 50 , (iv) 75 , (v) 100, (vi) 150, (vii) 200 and (viii) $250 \mathrm{mV} \mathrm{s}^{-1}$. The inset shows the plots of $\ln \left(/_{\mathrm{p}}\right)$ versus $\ln (v)$ for (1) cathodic and (2) anodic peaks.
Table 2 Electrochemical parameters of the cyclic voltammograms of $10 \mathrm{mM} \mathrm{Pu}(\mathrm{IV})$ in $1 \mathrm{M} \mathrm{H}_{2} \mathrm{SO}_{4}$ solution on $\mathrm{rGO} / \mathrm{GC}$ electrode at different scan rates $(v)$

\begin{tabular}{lllllllll}
\hline$v / \mathrm{V} \mathrm{s}^{-1}$ & $E_{\mathrm{p}}^{\mathrm{c}} / \mathrm{V}$ & $E_{\mathrm{p} / 2}^{\mathrm{c}} / \mathrm{V}$ & $E_{\mathrm{p}}^{\mathrm{a}} / \mathrm{V}$ & $E_{\mathrm{p} / 2}^{\mathrm{a}} / \mathrm{V}$ & $\Delta E_{\mathrm{p}} / \mathrm{V}$ & $E_{0}^{\prime} / \mathrm{V}$ & $n^{*} \alpha_{\mathrm{c}}$ & $n^{*} \alpha_{\mathrm{a}}$ \\
\hline 0.010 & 0.398 & 0.539 & 0.605 & 0.530 & 0.207 & 0.501 & 0.34 & 0.64 \\
0.025 & 0.358 & 0.530 & 0.617 & 0.542 & 0.259 & 0.488 & 0.28 & 0.64 \\
0.050 & 0.319 & 0.517 & 0.629 & 0.551 & 0.310 & 0.474 & 0.24 & 0.61 \\
0.075 & 0.295 & 0.507 & 0.637 & 0.558 & 0.342 & 0.466 & 0.22 & 0.60 \\
0.100 & 0.279 & 0.497 & 0.641 & 0.562 & 0.362 & 0.460 & 0.22 & 0.60 \\
0.150 & 0.247 & 0.480 & 0.652 & 0.566 & 0.405 & 0.449 & 0.20 & 0.55 \\
0.200 & 0.225 & 0.467 & 0.659 & 0.570 & 0.434 & 0.442 & 0.20 & 0.54 \\
0.250 & 0.210 & 0.451 & 0.667 & 0.577 & 0.457 & 0.439 & 0.19 & 0.53
\end{tabular}

Extended studies were performed to explore the applicability of $\mathrm{rGO} / \mathrm{GC}$ for the simultaneous determination of uranium and plutonium in the sample solution. Fig. $6 \mathrm{~b}$ shows six cathodic SWV (CSWV) for the reduction of $\mathrm{U}(\mathrm{VI}) / \mathrm{U}(\mathrm{IV})$ in the same samples in the potential range $0 \mathrm{~V}$ to $-0.65 \mathrm{~V}$. Surprisingly, a strange non-repeatability in $\mathrm{CSWV}$ of $\mathrm{U}(\mathrm{vI}) / \mathrm{U}(\mathrm{Iv})$ redox reaction is observed. The peak current is increased continuously with each repetition of CSWV recorded under identical conditions
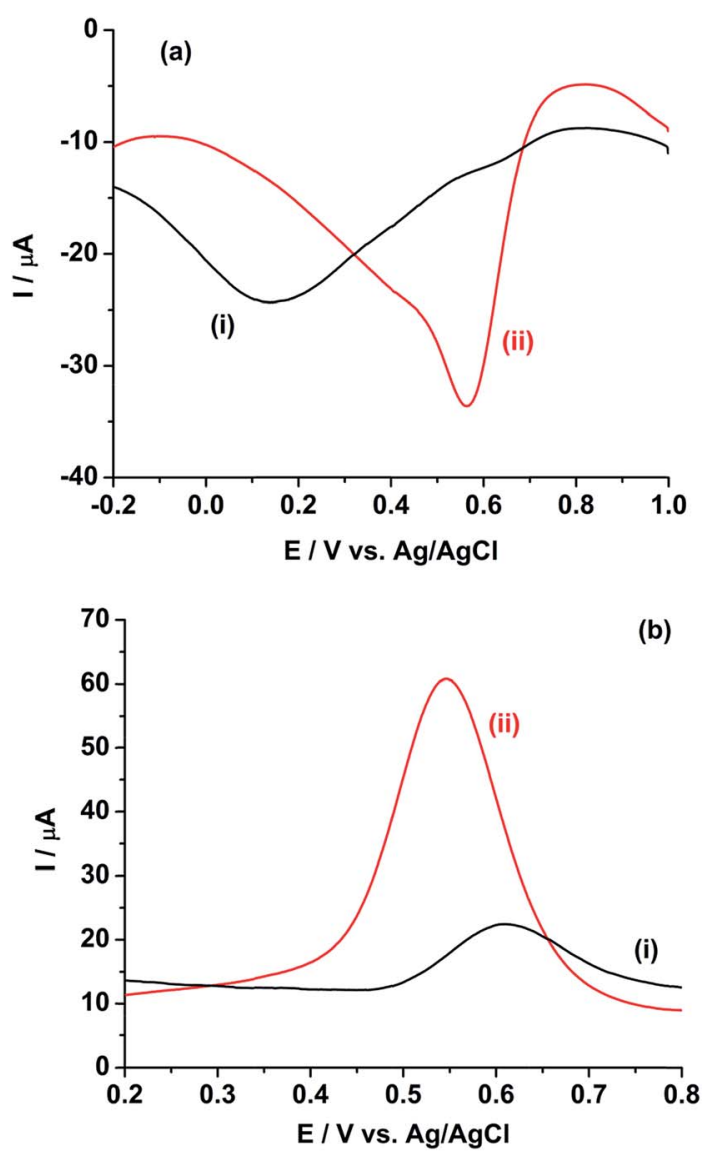

Fig. 4 Square wave voltammograms of $10 \mathrm{mM} \mathrm{Pu}(\mathrm{IV})$ in $1 \mathrm{M} \mathrm{H}_{2} \mathrm{SO}_{4}$ solution on (i) GC and (ii) rGO/GC electrodes in the (a) cathodic and (b) anodic scan directions. Square wave amplitude $=25 \mathrm{mV}$; square wave frequency $=20 \mathrm{~Hz}$; step potential increment $=1 \mathrm{mV}$; hold time at initial potential $=10 \mathrm{~s}$. 


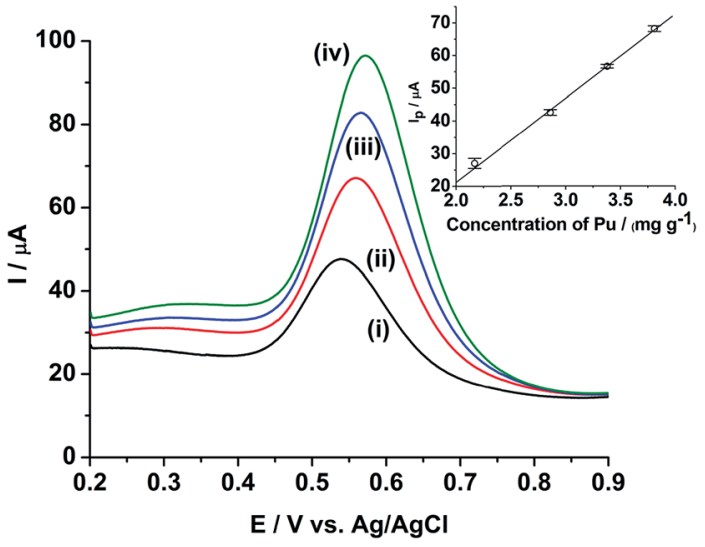

Fig. 5 ASWVs of (i) 2.17, (ii) 2.86, (iii) 3.38 and (iv) $3.81 \mathrm{mg} \mathrm{g}^{-1}$ of Pu in 1 $\mathrm{M} \mathrm{H}_{2} \mathrm{SO}_{4}$ on $\mathrm{rGO} / \mathrm{GC}$. Square wave amplitude $=25 \mathrm{mV}$; square wave frequency $=20 \mathrm{~Hz}$; step potential increment $=1 \mathrm{mV}$; hold time at initial potential $=10 \mathrm{~s}$. Inset shows the sensitivity plot for the same. The vertical bars shown in the inset represent the standard deviation $(\sigma)$ of $I_{p}$ obtained from ten replicate measurements for each concentration of $\mathrm{Pu}$.

(Fig. 6b) and this is repetitively confirmed. Thus, cyclic voltammetry experiment is performed with the same sample on $\mathrm{rGO} / \mathrm{GC}$ to investigate the cause of the instability in the cathodic peak of uranium. Fig. 7a shows the cyclic voltammogram of the sample on $\mathrm{rGO} / \mathrm{GC}$ in the potential range $1.1 \mathrm{~V}$ and $-0.7 \mathrm{~V}$ for continuous 15 cycles at a scan rate of $50 \mathrm{mV} \mathrm{s}^{-1}$. The cathodic peak current of $\mathrm{U}(\mathrm{vI}) / \mathrm{U}(\mathrm{Iv})$ reaction is increased significantly during the forward scan (i.e., scanning towards the negative potentials) in each successive cycle. Interestingly, the cathodic peak current of $\mathrm{Pu}(\mathrm{IV}) / \mathrm{Pu}(\mathrm{III})$ is also changed accordingly. The anodic peak current of $\mathrm{Pu}(\mathrm{IV}) / \mathrm{Pu}$ (III) reaction is also varied by $6.14 \%$ in presence of uranium and this variation is notably not observed in the cyclic voltammograms of $\mathrm{rGO} / \mathrm{GC}$ in pure plutonium solution.

Therefore, either (1) rGO/GC or (2) Pu leads to the autocatalytic reduction of $\mathrm{U}(\mathrm{vI})$ in the FBTR sample. ${ }^{46}$ Therefore, a similar experiment is performed on GC electrode. Fig. 7b shows the cyclic voltammogram of the sample on GC in the potential range of $1.1 \mathrm{~V}$ to $-0.7 \mathrm{~V}$ for continuous 15 cycles at a scan rate of $50 \mathrm{mV} \mathrm{s}^{-1}$. The cathodic peak current of $\mathrm{U}(\mathrm{vI}) / \mathrm{U}(\mathrm{Iv})$ reaction is similarly increased during the forward scan (i.e., scanning towards the negative potentials) in each successive cycle. This indicates that $\mathrm{rGO} / \mathrm{GC}$ (or the type of the working electrode) is not responsible for the instability of the cathodic peak current of $\mathrm{U}(\mathrm{vI}) / \mathrm{U}(\mathrm{Iv})$ in the sample solution; rather the presence of plutonium plays a crucial role in this autocatalytic reaction. That intuition is confirmed by the cyclic voltammograms of 5 $\mathrm{mM} \mathrm{U}(\mathrm{vI})$ solution in $1 \mathrm{M} \mathrm{H}_{2} \mathrm{SO}_{4}$ on (a) rGO/GC and (b) GC electrode at the scan rate of $50 \mathrm{mV} \mathrm{s}^{-1}$ (Fig. 8). The cathodic peak current of $\mathrm{U}(\mathrm{vI}) / \mathrm{U}(\mathrm{Iv})$ reaction is decreased in each successive cycle for both the electrodes. The oxidation of $\mathrm{U}(\mathrm{vI}) /$ $\mathrm{U}(\mathrm{Iv})$ is rather slow during the positive potential scan due to the formation of metal oxygen bond. Therefore, the decrease in the cathodic peak in each successive cycle is attributed to the decrease in the effective electrode surface area due to the
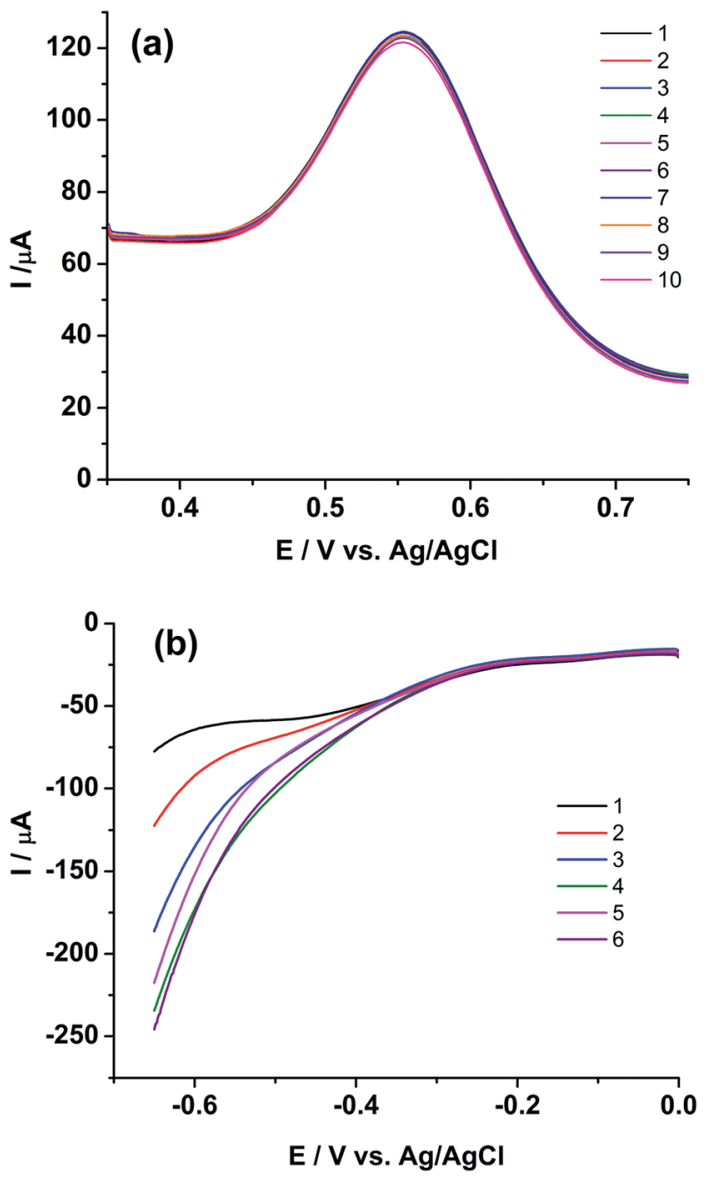

Fig. 6 Square wave voltammograms of (U, Pu)C FBTR sample on rGO/ $\mathrm{GC}$ for (a) anodic scan from $0.35 \mathrm{~V}$ to $0.75 \mathrm{~V}$ for analyzing $\mathrm{Pu}$ and (b) cathodic scan from $0 \mathrm{~V}$ to $-0.65 \mathrm{~V}$ for analyzing $\mathrm{U}$. Square wave amplitude $=25 \mathrm{mV}$; square wave frequency $=20 \mathrm{~Hz}$; step potential increment $=1 \mathrm{mV}$; standby time at $0.35 \mathrm{~V}$ (for a) and at $0 \mathrm{~V}$ (for b) is 10 $\mathrm{s}$. The numeric represents the sequence of the replicate measurements.

deposition of insoluble uranium(Iv) sulphate species on electrode. ${ }^{47,48}$ Moreover, for almost same amount of $\mathrm{U}(\mathrm{vI})(\sim 5-6$ $\mathrm{mM})$, the cathodic peak current of $\mathrm{U}(\mathrm{vI}) / \mathrm{U}(\mathrm{Iv})$ reaction in pure $\mathrm{U}(\mathrm{vI})$ solution is observed as almost one third of the corresponding peak current observed in the sample solution. Therefore, in corroboration with the interfacial redox interferences of U(IV) and Pu(IV) as discussed in the introduction, it is proved that the reduction of $\mathrm{U}(\mathrm{vI}) / \mathrm{U}(\mathrm{Iv})$ is auto-catalysed by the presence of $\mathrm{Pu}(\mathrm{IV})$ in $1 \mathrm{M} \mathrm{H}_{2} \mathrm{SO}_{4} \cdot{ }^{49,50}$

Fig. 9 shows a comprehensive representation of the autocatalytic reduction of $\mathrm{U}(\mathrm{VI})$ in the presence of $\mathrm{Pu}(\mathrm{Iv})$ in the FBTR fuel sample solution in $1 \mathrm{M} \mathrm{H}_{2} \mathrm{SO}_{4}$. The sample solution contains uranium in $\mathrm{U}(\mathrm{vI})$ state and plutonium in $\mathrm{Pu}(\mathrm{Iv})$ and $\mathrm{Pu}(\mathrm{vI})$ (to some extent) states (Zone I of the first cycle). During the potential scan towards the cathodic direction, $\mathrm{Pu}(\mathrm{Iv})$ and $\mathrm{Pu}(\mathrm{VI})$ are electrochemically reduced to $\mathrm{Pu}(\mathrm{III})$ at the working electrode as shown in the Zone II. After the cathodic peak of $\mathrm{Pu}$, the mass transfer of $\mathrm{Pu}(\mathrm{Iv})$ and $\mathrm{Pu}(\mathrm{vI})$ towards the working electrode becomes diffusion controlled (Zone III), but U(vi) exists as it is in the solution. In Zone IV, the U(vI) starts 

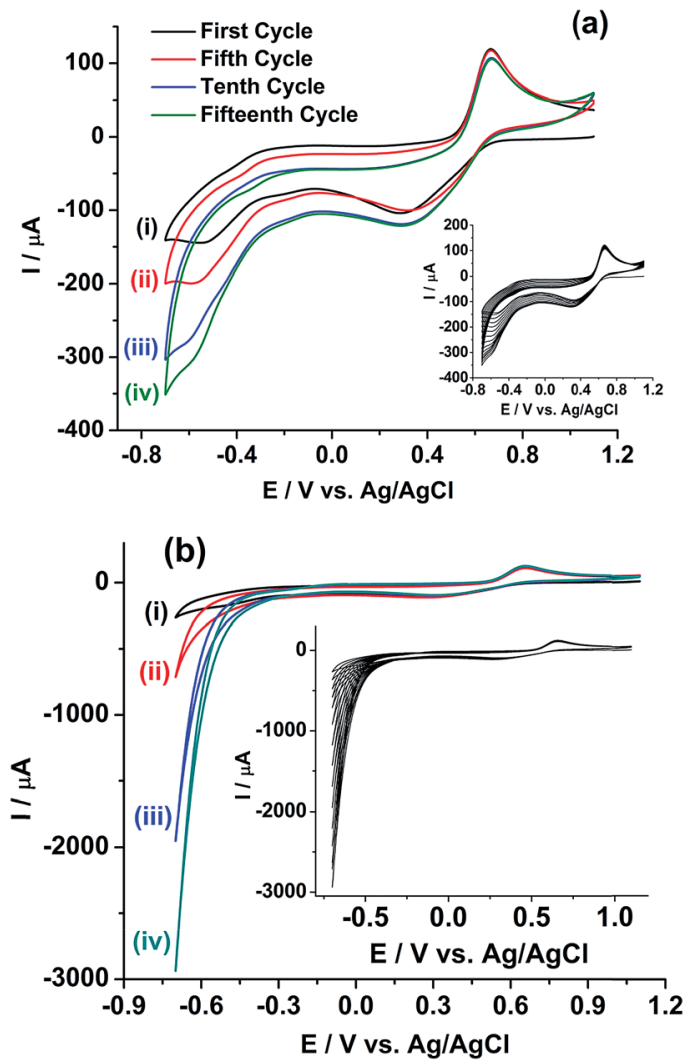

Fig. 7 Cyclic voltammograms of (U, Pu)C FBTR fuel sample on (a) $\mathrm{rGO} / \mathrm{GC}$ and (b) GC electrodes at a scan rate of $50 \mathrm{mV} \mathrm{s}^{-1}$ for (i) first, (ii) fifth, (iii) tenth and (iv) fifteenth cycle. The insets show the continuous cyclic voltammograms of 15 cycles.

electrochemically reduced to $\mathrm{U}(\mathrm{Iv})$ and gets deposited on the working electrode as uranium(Iv)-sulphate species, which comes into the direct contact of the diffusing Pu(IV) near to the working electrode. Therefore, $\mathrm{U}(\mathrm{vI})$ is regenerated near the electrode solution interface by the chemical reaction with $\mathrm{Pu}(\mathrm{Iv})$ following eqn (8) and it leads to the higher reduction current of uranium.

$$
\begin{array}{r}
2[\mathrm{Pu}(\mathrm{IV})]^{4+}+[\mathrm{U}(\mathrm{IV})]^{4+}+2 \mathrm{H}_{2} \mathrm{O} \\
=2[\mathrm{Pu}(\mathrm{III})]^{3+}+\left[\mathrm{U}(\mathrm{VI}) \mathrm{O}_{2}\right]^{2+}+4 \mathrm{H}^{+}
\end{array}
$$

The reaction (8) is very fast in $\mathrm{H}_{2} \mathrm{SO}_{4}$ medium. ${ }^{49,50}$ This reaction in addition to the diffusion controlled mass transfer of both $\mathrm{U}(\mathrm{vI})$ and $\mathrm{Pu}(\mathrm{Iv})$ continues in the Zone $\mathrm{V}$ although the scan direction is reversed. The reduction of $\mathrm{U}(\mathrm{VI})$ stops in Zone VI; but the remaining $\mathrm{U}(\mathrm{Iv})$ deposit, if still exists on the working electrode at all, continuously reacts with the $\mathrm{Pu}(\mathrm{Iv})$ diffusing from the bulk of the solution towards the working electrode. Therefore, $\mathrm{U}(\mathrm{VI})$ accumulates near the working electrode. The $\mathrm{Pu}(\mathrm{III})$ generated till Zone VI, starts oxidising in Zone VII to Pu(rv) on the electrode. The $\mathrm{Pu}(\mathrm{rv})$ is preferentially stabilized by the supporting electrolyte $\left(1 \mathrm{M} \mathrm{H}_{2} \mathrm{SO}_{4}\right.$ ) compared to $\mathrm{Pu}(\mathrm{III})$. The diffusion controlled oxidation of $\mathrm{Pu}(\mathrm{III})$ occurs in Zone VIII. The fraction of $\mathrm{Pu}(\mathrm{Iv})$ in the sample solution increases after
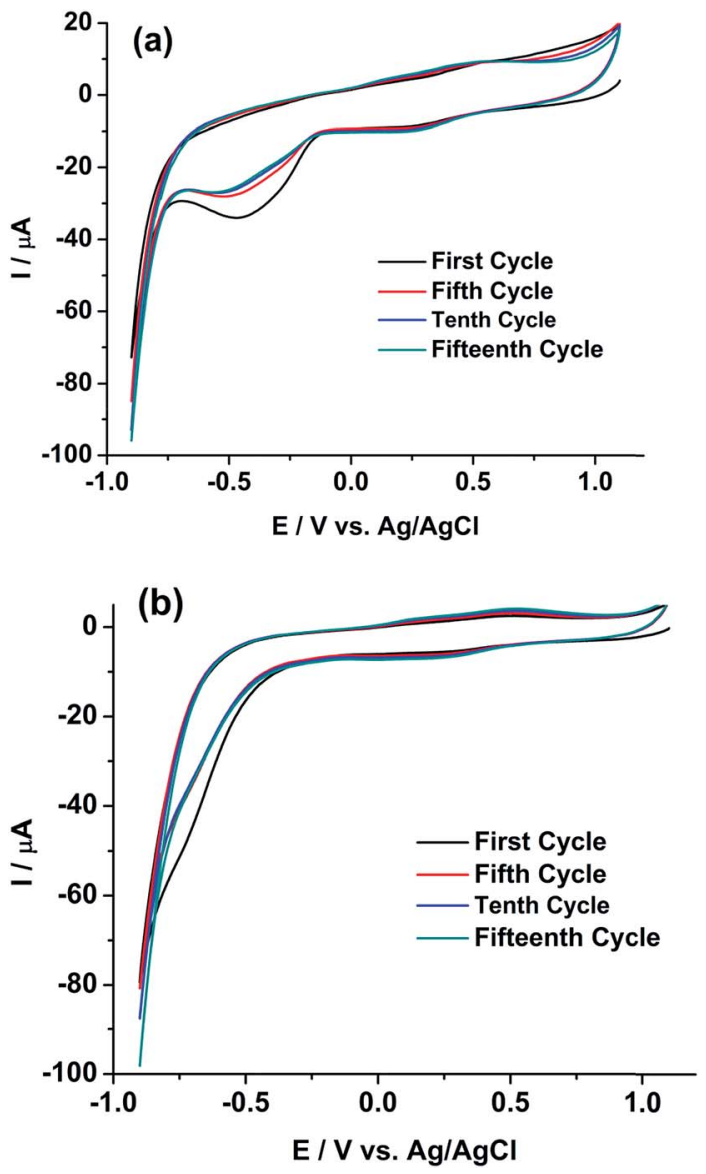

Fig. 8 Cyclic voltammograms of $5 \mathrm{mM} \mathrm{U}(\mathrm{vl})$ in $1 \mathrm{M} \mathrm{H}_{2} \mathrm{SO}_{4}$ on (a) $\mathrm{rGO}$ / GC and (b) GC electrodes at a scan rate of $50 \mathrm{mV} \mathrm{s}^{-1}$ for (i) first, (ii) fifth, (iii) tenth and (iv) fifteenth cycle.

completion of each cycle resulting into an increase in the flux of $\mathrm{Pu}(\mathrm{Iv})$ from bulk of the solution to the working electrode assisting in the autocatalytic reduction of $\mathrm{U}(\mathrm{vI})$. Therefore, it is understood that unless a strategic methodology could be developed, the quantitative voltammetric measurement of $\mathrm{U}(\mathrm{vI})$ in the presence of $\mathrm{Pu}(\mathrm{Iv})$ in $1 \mathrm{M} \mathrm{H}_{2} \mathrm{SO}_{4}$ is not advisable on either any simple or modified working electrode.

Therefore, we have restricted our following studies to $\mathrm{Pu}$ only. Fig. 10(a) shows the ASWV of the blank $\mathrm{H}_{2} \mathrm{SO}_{4}$ on $\mathrm{rGO} / \mathrm{GC}$ electrode (i). The anodic peak of the $\mathrm{Pu}(\mathrm{Iv}) / \mathrm{Pu}$ (III) redox couple of the sample is appeared at $0.541 \mathrm{~V}$ with the peak current of 62.14 $\pm 1.08 \mu \mathrm{A}$ (ii). The anodic peak current of the same reaction is increased systematically for the addition of (iii) $1.088 \mathrm{mg} \mathrm{g}^{-1}$, (iv) $1.904 \mathrm{mg} \mathrm{g}^{-1}$, (v) $2.539 \mathrm{mg} \mathrm{g}^{-1}$ and (vi) $3.047 \mathrm{mg} \mathrm{g}^{-1}$ of standard plutonium solution into the sample. Fig. 10(b) shows the mean peak current (along with the standard deviation for ten number of repeatable measurements) of the sample at 0 value of the $x$-axis. The mean peak currents (along with the standard deviation for ten number of repeatable measurements) for each standard addition of plutonium is increased linearly with a sensitivity of $12.5 \mu \mathrm{A}\left(\mathrm{mg} \mathrm{g}^{-1}\right)^{-1}$; which is much lower compared to the sensitivity of $\mathrm{rGO} / \mathrm{GC}$ observed $(25.8 \mu \mathrm{A}$ $\left.\left(\mathrm{mg} \mathrm{\textrm {g } ^ { - 1 }}\right)^{-1}\right)$ in pure plutonium solution. Therefore, the 


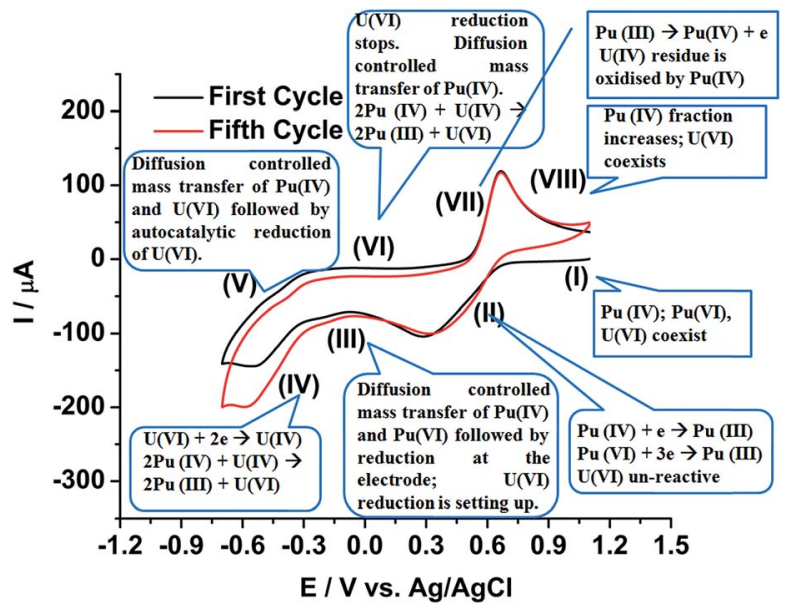

Fig. 9 Comprehensive representation of the autocatalytic reduction of $\mathrm{U}(\mathrm{VI})$ in the FBTR fuel sample solution containing both uranium and plutonium in $1 \mathrm{M} \mathrm{H}_{2} \mathrm{SO}_{4}$.
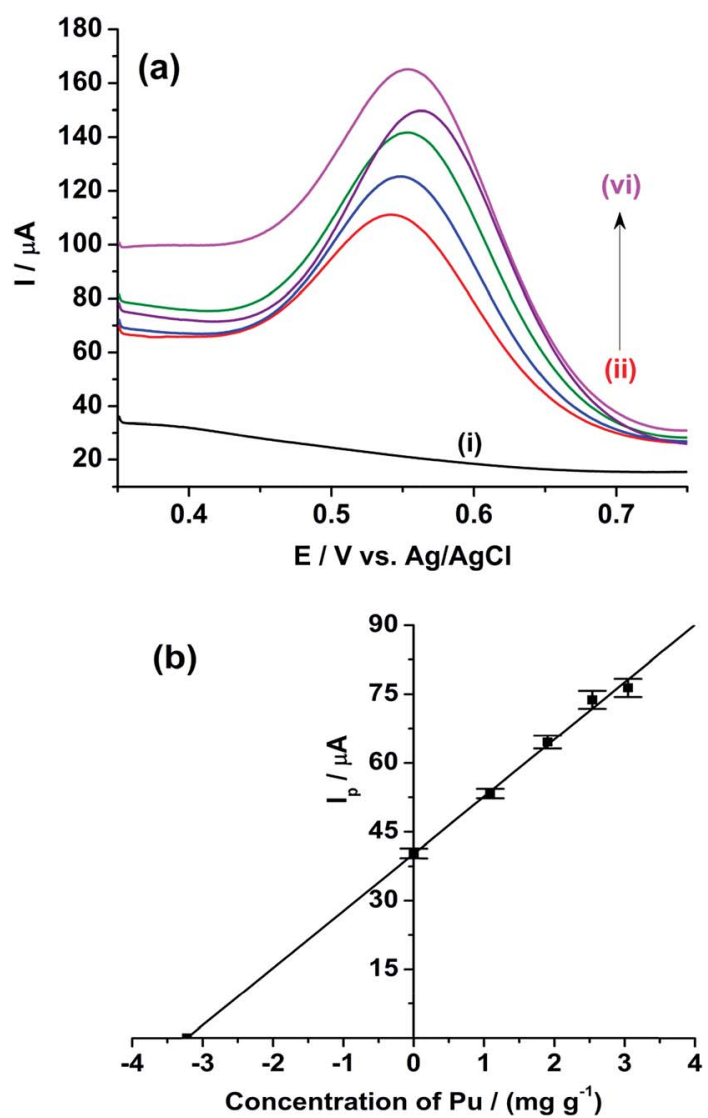

Fig. 10 ASWVs of the (i) blank $1 \mathrm{M} \mathrm{H}_{2} \mathrm{SO}_{4}$ (ii) of (U, Pu)C FBTR sample in $1 \mathrm{M} \mathrm{H}_{2} \mathrm{SO}_{4}$ and standard addition of (iii) $1.088 \mathrm{mg} \mathrm{g}^{-1}$, (iv) $1.904 \mathrm{mg} \mathrm{g}^{-1}$, (v) $2.539 \mathrm{mg} \mathrm{g}^{-1}$ and (vi) $3.047 \mathrm{mg} \mathrm{g}^{-1}$ of standard plutonium solution into the sample solution. Square wave amplitude $=25 \mathrm{mV}$; square wave frequency $=20 \mathrm{~Hz}$; step potential increment $=1 \mathrm{mV}$; standby time at $0.35 \mathrm{~V}$ is $10 \mathrm{~s}$. The error bars represent the standard deviation for ten repetitive measurements.

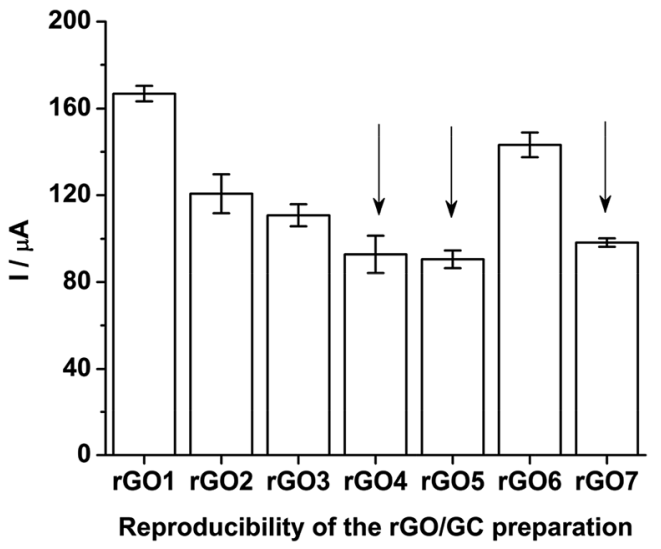

Fig. 11 ASWV peak currents of $\mathrm{Pu}(\mathrm{IV}) / \mathrm{Pu}(\mathrm{III})$ redox couple recorded on seven $\mathrm{rGO} / \mathrm{GCs}$ in the final test solution (i.e.; sample $+3.047 \mathrm{mg} \mathrm{g}^{-1}$ of standard $\mathrm{Pu}$ ). The error bars represent the standard deviation for ten repetitive measurements. The arrows show the rGO/GCs selected for the ANOVA test

coexistence of uranium decreases the sensitivity of the voltammetric determination of plutonium. The sensitivity of the GC electrode for the same type of analysis is calculated as $5.35 \mu \mathrm{A}$ $\left(\mathrm{mg} \mathrm{g}^{-1}\right)^{-1}$. The concentration of plutonium in the sample is evaluated as $3.222 \pm 0.179 \mathrm{mg} \mathrm{g}^{-1}$ by extrapolating the straight line to the negative $x$-axis intercept (i.e. considering the $y$-axis value as 0) (Fig. 10(b)). The relative accuracy error (from the biamperometric result) and the relative standard deviation (of ASWV results) are calculated as $-15 \%$ and $5.5 \%$, respectively. Therefore, it is clear that there is enough scope to increase the analytical merits of the voltammetric determination of plutonium in $(\mathrm{U}, \mathrm{Pu}) \mathrm{C}$ samples.

Seven $\mathrm{rGO} / \mathrm{GC}$ electrodes are prepared under the previously discussed optimized method. The mean ASWV peak currents (along with the standard deviation for ten number of repeatable measurements) of $\mathrm{Pu}(\mathrm{Iv}) / \mathrm{Pu}(\mathrm{III})$ couple recorded with seven $\mathrm{rGO} /$ GCs in the final test solution (i.e.; sample $+3.047 \mathrm{mg} \mathrm{g}^{-1}$ of standard $\mathrm{Pu}$ ) is shown in Fig. 11. The variation in the peak current values is attributed to the variation in the surface coverage of the rGO on the actual GC surface. It should be noted that the drop casting operation of GO on GC electrode followed by slow drying under IR lamp inside a radioactive fume hood or glove box is a tedious job justifying the variation in the relative surface coverage of rGO on GC electrode. Among the seven rGO/ GCs; three electrodes (i.e. rGO4. rGO5 and rGO7) belong to the same class with $99 \%$ confidence level $(0.05<p$-significance $<$ 0.01 for $F(2,27)=4.97)$. Further, the $\mathrm{rGO} / \mathrm{GC}$ electrodes have showed very robust performance during the electroanalysis of actinides in acid solutions and no significant depreciation of the peak current is observed even after long operation period.

\section{Conclusions}

The aqueous electrochemistry of plutonium on $\mathrm{rGO} / \mathrm{GC}$ is systematically investigated for the first time in $1 \mathrm{M} \mathrm{H}_{2} \mathrm{SO}_{4}$. The increase in the extent of the reversibility as well as the enhancement of the electron transfer rate constant of $\mathrm{Pu}(\mathrm{Iv}) /$ 
$\mathrm{Pu}(\mathrm{III})$ redox reaction confirms that $\mathrm{rGO} / \mathrm{GC}$ can catalyse the redox chemistry of $\mathrm{Pu}(\mathrm{Iv}) / \mathrm{Pu}(\mathrm{III})$. For the voltammetric determination of $\mathrm{Pu}$ in $1 \mathrm{M} \mathrm{H}_{2} \mathrm{SO}_{4}$, the anodic voltammetric peak representing the oxidation of $\mathrm{Pu}(\mathrm{III})$ to $\mathrm{Pu}(\mathrm{Iv})$ is more suitable compared to the cathodic voltammetric peak representing the reduction of $\mathrm{Pu}(\mathrm{IV})$ to $\mathrm{Pu}(\mathrm{III})$. In standard $\mathrm{Pu}$ solution, $\mathrm{rGO} / \mathrm{GC}$ shows higher sensitivity for the determination of $\mathrm{Pu}$ compared to the bare GC electrode. However, the sensitivity of $\mathrm{rGO} / \mathrm{GC}$ electrode decreases in the test sample solution due to the interference of uranium. Moreover, it is evidenced that the cathodic reaction of $\mathrm{U}(\mathrm{vI}) / \mathrm{U}(\mathrm{IV})$ redox couple is autocatalysed by the reaction with $\mathrm{Pu}(\mathrm{Iv})$ diffusing from the bulk of the solution to the vicinity of the working electrode. That autocatalytic cathodic reaction of $\mathrm{U}(\mathrm{vI})$ is observed for both $\mathrm{GC}$ and $\mathrm{rGO} / \mathrm{GC}$ electrodes. Therefore, from the reported evidences and according to our present understandings, it can be concluded that uranium cannot be determined quantitatively in the presence of plutonium on solid electrodes (irrespective of the type of surface modifications) by simple voltammetric methods. Although rGO/GC shows good analytical robustness, reproducibility, repeatability, requirement of no additional reagents as well as lesser operational duration; but the analytical merit for the determination of $\mathrm{Pu}$ in nuclear fuel sample is not very competitive to the biamperometric method. Therefore, a scope of research still exists for the development of simple, fast, robust, precise and accurate electroanalytical methods for the simultaneous determination of $\mathrm{U}$ and $\mathrm{Pu}$ in nuclear fuel.

\section{Notes and references}

1 http://www.npcil.nic.in/main/AllProjectOperationDisplay.aspx, 2015.

2 G. Srinivasan, K. V. Suresh Kumar, B. Rajendran and P. V. Ramalingam, Nucl. Eng. Des., 2006, 236, 796-811.

3 T. Hashimoto, K. Taniguchi, H. Sugiyama and T. Sotobayashi, J. Radioanal. Chem., 1979, 52, 133-142.

4 K. Suresh Kumar, P. Magesvaran, D. Sreejeya, T. Kumar, B. Shreekumar and P. K. Dey, J. Radioanal. Nucl. Chem., 2010, 284, 457-460.

5 A. N. Dubey, G. R. Relan and S. Vaidyanathan, J. Radioanal. Nucl. Chem., 1999, 240, 741-746.

6 L. Couston, J. Delage and D. Pouyat, Direct, remote, and simultaneous determination of uranium and plutonium in eight different media by optical absorptometry using nonimmersed optical fibre sensors, Proc. SPIE 3483, European Workshop on Optical Fibre Sensors, 1998.

7 G. R. Relan, A. N. Dubey and S. Vaidyanathan, J. Radioanal. Nucl. Chem., 1996, 204, 15-22.

8 C.-G. Lee, D. Suzuki, Y. Saito-Kokubu, F. Esaka, M. Magara and T. Kimura, Int. J. Mass Spectrom., 2012, 314, 57-62.

9 R. Kapsimalis, D. Glasgow, B. Anderson and S. Landsberger, J. Radioanal. Nucl. Chem., 2013, 298, 1721-1726.

10 N. Gopinath, G. A. Rama Rao, V. K. Manchanda and P. R. Natarajan, J. Radioanal. Nucl. Chem., 1985, 96, 273-280.

11 A. R. Eberle, M. W. Lerner, C. G. Goldbeck and C. J. Rodden, Titrimetric determination of uranium in products, fuel and scrap materials after ferrous ion reduction in phosphoric acid, New Brunswick Laboratory, 1970.

12 P. R. Nair, K. V. Lohithakshan, M. Xavier, S. G. Marathe and H. C. Jain, J. Radioanal. Nucl. Chem., 1988, 122, 19-26.

13 G. A. Rama Rao, V. K. Manchanda and P. R. Natarajan, J. Radioanal. Nucl. Chem., 1985, 94, 95-100.

14 M. Xavier, P. R. Nair, K. V. Lohithakshan, S. G. Marathe and H. C. Jain, J. Radioanal. Nucl. Chem., 1991, 148, 251-256.

15 M. V. Ramaniah, P. R. Natarajan and P. Venkataramana, Radiochim. Acta, 1975, 22, 199-213.

16 P. R. Nair, M. Xavier and S. K. Aggarwal, Radiochim. Acta, 2009, 97, 419-422.

17 P. H. Chadwick and I. R. McGowan, Talanta, 1972, 19, 13351348.

18 W. Davies and W. Gray, Talanta, 1964, 11, 1203-1211.

19 J. L. Drummond and R. A. Grant, Talanta, 1966, 13, 477-488. 20 W. D. Shults, Talanta, 1963, 10, 833-849.

21 G. W. C. Milner, G. Phillips and A. J. Fudge, Talanta, 1968, 15, 1241-1257.

22 J. E. Harrar, Electroanalytical chemistry, Marcel Dekker, New York, 1975.

23 T. Tanaka, G. Marinenko and W. F. Koch, Talanta, 1985, 32, 525-530.

24 H. S. Sharma, N. B. Khedekar, S. G. Marathe and H. C. Jain, Nucl. Technol., 1990, 89, 399-405.

25 H. S. Sharma, V. Jisha, D. M. Noranha, M. K. Sharma and S. K. Aggarwal, Performance evaluation of indigenous controlled potential coulometer for the determination of uranium and plutonium, 2007, BARC Report, BARC/2007/E/ 012.

26 M. K. Sharma, J. V. Kamat, A. S. Ambolikar, J. S. Pillai and S. K. Aggarwal, Coulometry for the determination of uranium and plutonium: Past and present2012, BARC Report, BARC/ 2012/E/001.

27 N. Gopinath, N. N. Mirashi, K. Chander and S. K. Aggarwal, J. Appl. Electrochem., 2004, 34, 617-622.

28 H. S. Sharma, R. B. Manolkar, J. V. Kamat and S. G. Marathe, Fresenius. J. Anal. Chem., 1993, 347, 486-490.

29 A. R. Joshi and U. M. Kasar, J. Radioanal. Nucl. Chem., 1991, 150, 483-491.

30 S. K. Guin, J. S. Pillai, A. S. Ambolikar, A. Saha and S. K. Aggarwal, RSC Adv., 2013, 3, 17977-17988.

31 S. K. Guin, A. S. Ambolikar and J. V. Kamat, Electrochim. Acta, 2015, 174, 1002-1008.

32 R. Gupta, K. Jayachandran and S. K. Aggarwal, RSC Adv., 2013, 3, 13491-13496.

33 R. Gupta, S. K. Guin and S. K. Aggarwal, RSC Adv., 2012, 2, 1810-1819.

34 K. D. Singh Mudher and K. Krishnan, J. Alloys Compd., 2000, 313, 65-68.

35 K. Chander, B. N. Patil, J. V. Kamat, N. B. Khedekar, R. B. Manolkar and S. G. Marathe, Nucl. Technol., 1987, 78, 69-74.

36 A. J. Bard and L. R. Faulkner, Electrochemical Methods: Fundamentals and Applications, Wiley, second edn, 2000.

37 R. S. Nicholson and I. Shain, Anal. Chem., 1965, 37, 178-190. 38 R. S. Nicholson and I. Shain, Anal. Chem., 1965, 37, 190-195. 
39 R. S. Nicholson, Anal. Chem., 1965, 37, 667-671.

40 R. S. Nicholson, Anal. Chem., 1965, 37, 1351-1355.

41 R. S. Nicholson and I. Shain, Anal. Chem., 1964, 36, 706-723.

42 J. Heinze, Angew. Chem., Int. Ed. Engl., 1984, 23, 831-847.

43 H. Matsuda and Y. Ayabe, Z. Elektrochem., 1955, 59, 494-503.

44 X. Liu, Y. Wen, B. Shan, K. Cho, Z. Chen and R. Chen, Appl. Phys. A, 2015, 118, 885-892.

45 C. Gómez-Navarro, J. C. Meyer, R. S. Sundaram, A. Chuvilin, S. Kurasch, M. Burghard, K. Kern and U. Kaiser, Nano Lett., 2010, 10, 1144-1148.
46 A. W. Bott, Curr. Sep., 1999, 18, 9-16.

47 D. Gil, R. Malmbeck, J. Spino, T. Fanghänel and E. Dinnebier Robert, Radiochim. Acta, 2010, 98, 77-89.

48 S. Suzuki, S. Hirono, Y. Awakura and H. Majima, Metall. Trans. B, 1990, 21, 839-844.

49 P. Biddle, J. H. Miles and M. J. Waterman, J. Inorg. Nucl. Chem., 1966, 28, 1736-1739.

50 T. W. Newton, J. Phys. Chem., 1959, 63, 1493-1497. 